\title{
One Case of Root Tip Foreign Body of Anterior Tooth Trauma
}

\author{
Xiaohui Zhu, Weiqun Guan \\ Fujian Medical University Union Hospital, Fujian, China \\ Email: zyf1062008@sina.com
}

How to cite this paper: Zhu, X.H. and Guan, W.Q. (2017) One Case of Root Tip Foreign Body of Anterior Tooth Trauma. Open Journal of Stomatology, 7, 353-360. https://doi.org/10.4236/ojst.2017.78030

Received: July 9, 2017

Accepted: August 11, 2017

Published: August 14, 2017

Copyright (C) 2017 by authors and Scientific Research Publishing Inc. This work is licensed under the Creative Commons Attribution International License (CC BY 4.0).

http://creativecommons.org/licenses/by/4.0/

\begin{abstract}
Patients with obsolete anterior tooth trauma often see a doctor because of dental stain or gingiva tumefaction and suppuration in clinical. In this case, a 28-year-old female patient took root canal therapy for repeated gingiva tumefaction and tooth stain in anterior teeth of left maxillary and giant foreign body at apex shown in X-ray photography. After removing the foreign body at apex by endodontic surgery, internal bleaching and resin repair were conducted. The therapy shows that the usage specification of hot gutta-percha should strictly follow the operational steps, while the necessity of X-ray photography after operation should be confirmed in clinical operation. In addition, internal bleaching and resin repair should be combined to obtain the success in clinical therapy.
\end{abstract}

\section{Keywords}

Dental Trauma, Foreign Body at Apex, Interior Tooth Bleaching

\section{Introduction}

Tooth trauma is a common disease in Department of Stomatology, and obsolete tooth trauma refers to a series of clinical symptoms in later period because the patient did not have treatment, did not have treatment in time, or interrupted the treatment after getting tooth trauma. Such symptoms include tooth stain, ankylosed tooth, internal and external root resorption, root fracture, apical abscess, apical cyst and odontoseisis caused by pulp necrosis. This work summarized and reported one case of apical abscess caused by irregular operation in root canal therapy for central incisor (obsolete tooth trauma) in the left maxillary as follows.

\section{Case Report}

A 28-year-old female patient was treated in Department of Stomatology, Fujian 
Medical University Union Hospital on March $11^{\text {th }} 2016$ with chief complaint of "gingiva of the left upper anterior tooth suppurated for one month". A decade ago, the patient had tooth trauma. One year ago, the patient had root canal therapy in other hospital for the $21^{\text {st }}$ tooth. One month ago, the patient was treated in our hospital for repeated suppuration at gingiva of the $21^{\text {st }}$ tooth. The patient is healthy in the past, denying systematic disease, infectious disease, drug allergy history, poisoning history and trauma history in last ten years. Clinical para-oral examination (Figures 1-2): The maxillofacial region is basically symmetrical in left and right; no tenderness in temporal-mandibular joint and no click and fricative when opening and closing mouth; parotid gland is normal in palpation; no swelling in lymph gland. Intraoral examination: there is tooth stain and fistula at gingiva in the $21^{\text {st }}$ tooth, the crown is dark and $21(++)$ is not loose, the teeth of the teeth were normal and the 11 teeth were cut by $1 / 3$. X-ray periapical film shows (Figure 3): $21^{\text {st }}$ tooth is low-density shadow under large-area and high-density projection at apex with defective root filling. The patient wanted to improve the tooth color without wearing too much tooth when solving the suppuration at apex.

Therapeutic methods: 1) another root canal therapy was conducted for the $21^{\text {st }}$ tooth to measure the length with endometer. However, root filling condition cannot be judged with the foreign body at apex by $\mathrm{X}$ ray, so operation of apex should be conducted immediately after root filling. 2) Crevicular incision. Crumby matter can be seen at apex in flaple. The matter was taken out from the apex (the texture is hard and elastic as hot gutta-percha with diameter of about 8

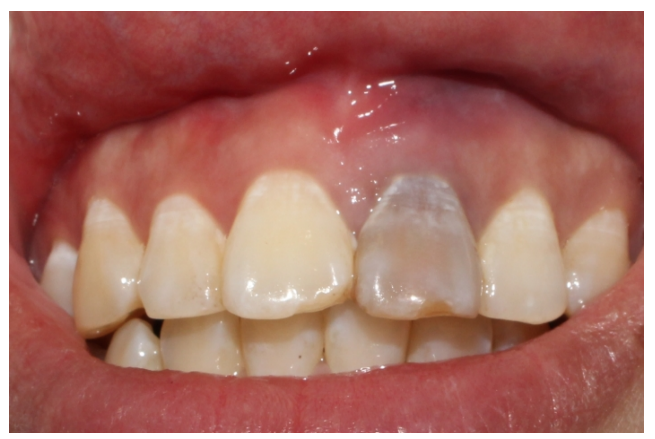

Figure 1. Discoloration of teeth after trauma.

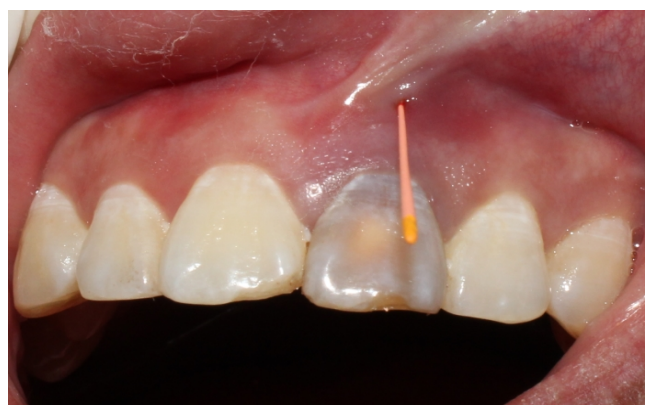

Figure 2. Gingival fistula. 


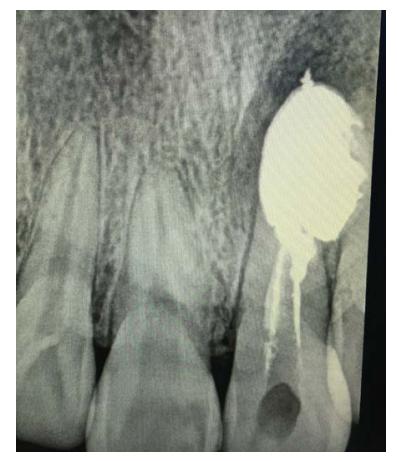

Figure 3. The root area is low density.

$\mathrm{mm}$ (Figures 4-6). 3) Scratch the apex and wash it with normal saline. Restore and suture the mandibular with minocycline smeared in partial (Figure 7). 4) Post-operative CBCT shows that root filling was improved and the resistant projection of agglomerate at apex disappeared (Figures 8-9). 5) Fistula disappeared 1 week after operation (Figure 10). 6) Intracoronal bleaching was conducted and then medical prescription was changed twice in follow-up visit. The color of $21^{\text {st }}$ tooth became 11 and 12 with resin repair at the incisal margin of $21^{\text {st }}$ tooth. 7) The color change of bleaching opisthosoma is relatively obvious than that in neck. The color of tooth neck is dark. The protective screen was established for the third bleaching. Four days later, further consultation was conducted with color of tooth neck improved. The patient was satisfied (Figure 11). 8) 1, 3, 6 and 12 months after operation, further consultation was conducted in follow-up (Figure 12).

\section{Discussion}

Root-canal filling technology with hot gutta-percha is the most applied rootcanal filling. Gutta-percha has liquidity after being softened by warming. By injecting appropriate pressure, gutta-percha can follow the complex morphology of root canal to pour to various parts in lumen. Finally, ideal three-dimensional root filling effects can be achieved. However, hot gutta-percha has good liquidity, injecting pressure is too large to have extrusion tendency [1]. Some experiment shows that only hot gutta-percha filling by good operation can decrease the possibility of extrusion [2]. The experiment by Yang Chunxia et al. [3] shows that the extrusion of hot gutta-percha is mainly the overflow of sealing agent from apical foramen, particularly in cases with larger lesion scope and damage at apex. Moreover, oversized dynamics when forcing may also cause the extrusion of sealing agent from apical foramen. Problems caused by hot gutta- percha are inadequate and small curved root canal and large pressure may cause extrusion and root fracture; high excess temperature in root canal may also cause periodontal damage in heating [4]. Some study applied hot gutta-percha vertical condensation for root canal filling. The type of filler should match with the size of taper in root canal preparation [5]. 


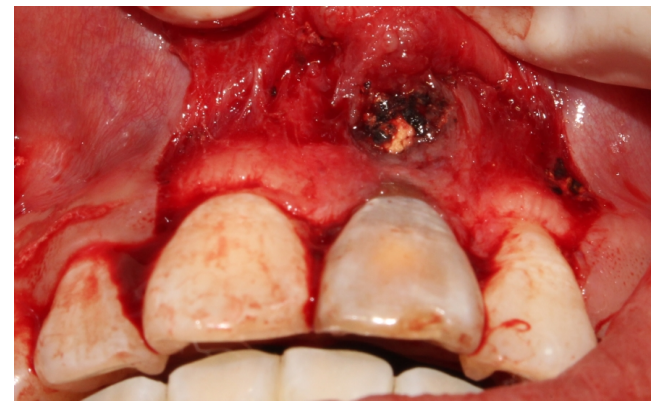

Figure 4. Open and flap the root tip of the and low density mass.

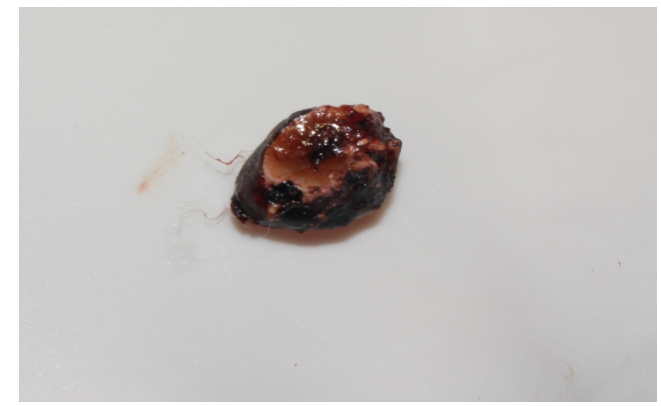

Figure 5. A complete extract.

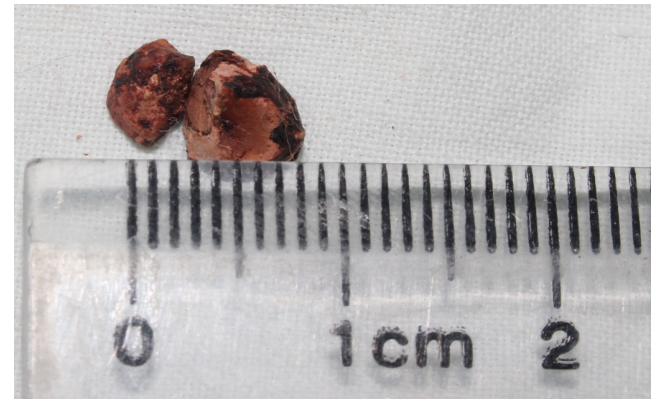

Figure 6. The size is about $0.7 \mathrm{~mm}$ in diameter.

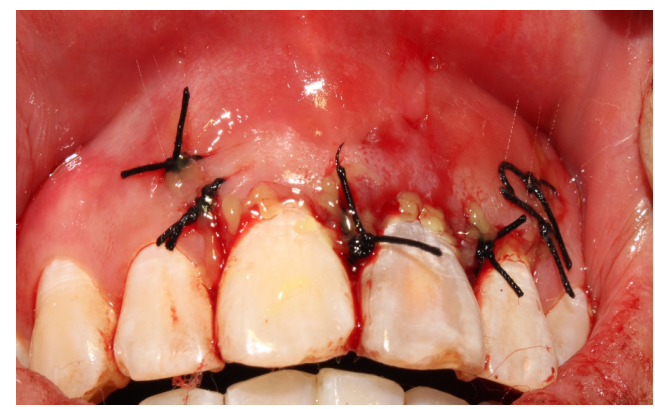

Figure 7. Suturing reattachment.

This patient is a typical case of a series of problems at apex caused by the extrusion of hot gutta-percha root canal filling out of apical foramen. Wide attention should be drawn from clinicians to the demands of taking out large foreign 


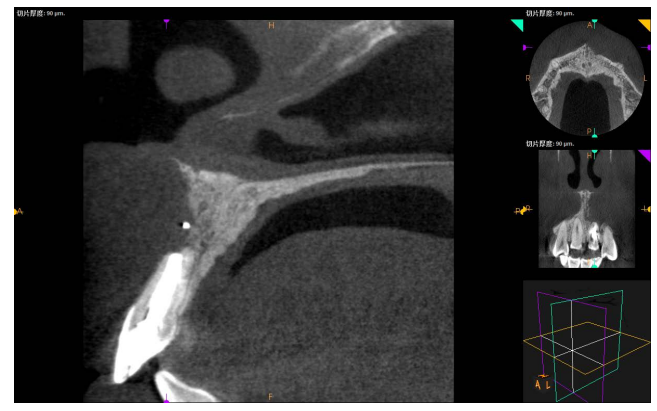

Figure 8. Postoperative CBCT showed that the root apex had no foreign matter root filling.
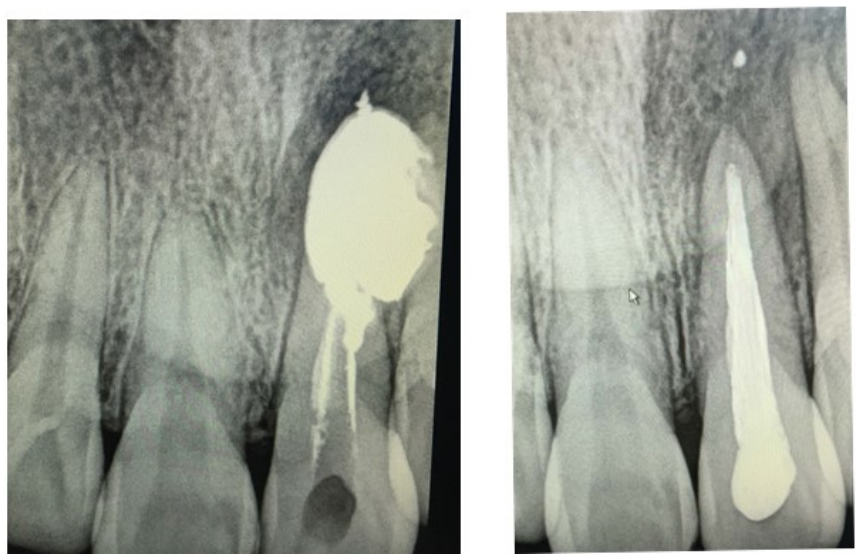

Figure 9. Preoperative X-ray films.

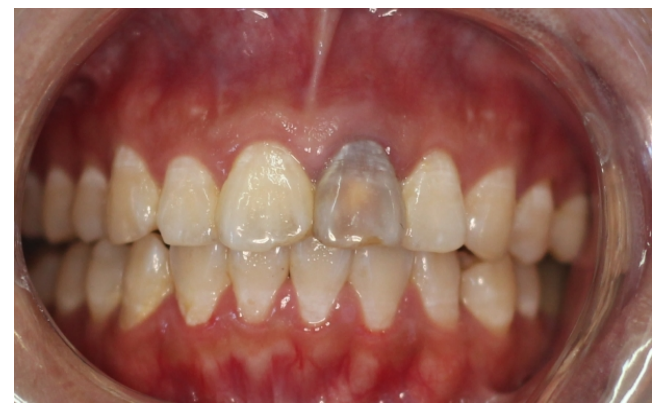

Figure 10. One week after surgery, the gum Fistula disappeared.

body (hot gutta-percha) from root top. This patient with tooth trauma may cause external root resorption and pathological increase of apical foramen for trauma. Or, the apical foramen was not developed for trauma and the apical foramen was not closed because the treatment was not in time, so the apical foramen was large. Because of above pathological and physiological characteristics of apical foramen and bad control over hot gutta-percha filling pressure, X-ray photography was not taken in time for prognosis. Therefore, the problem occurred.

Interior tooth bleaching of devital tooth is a conservative whitening method. The common products in clinical are $35 \%$ hydrogen peroxide and bleaching gel 

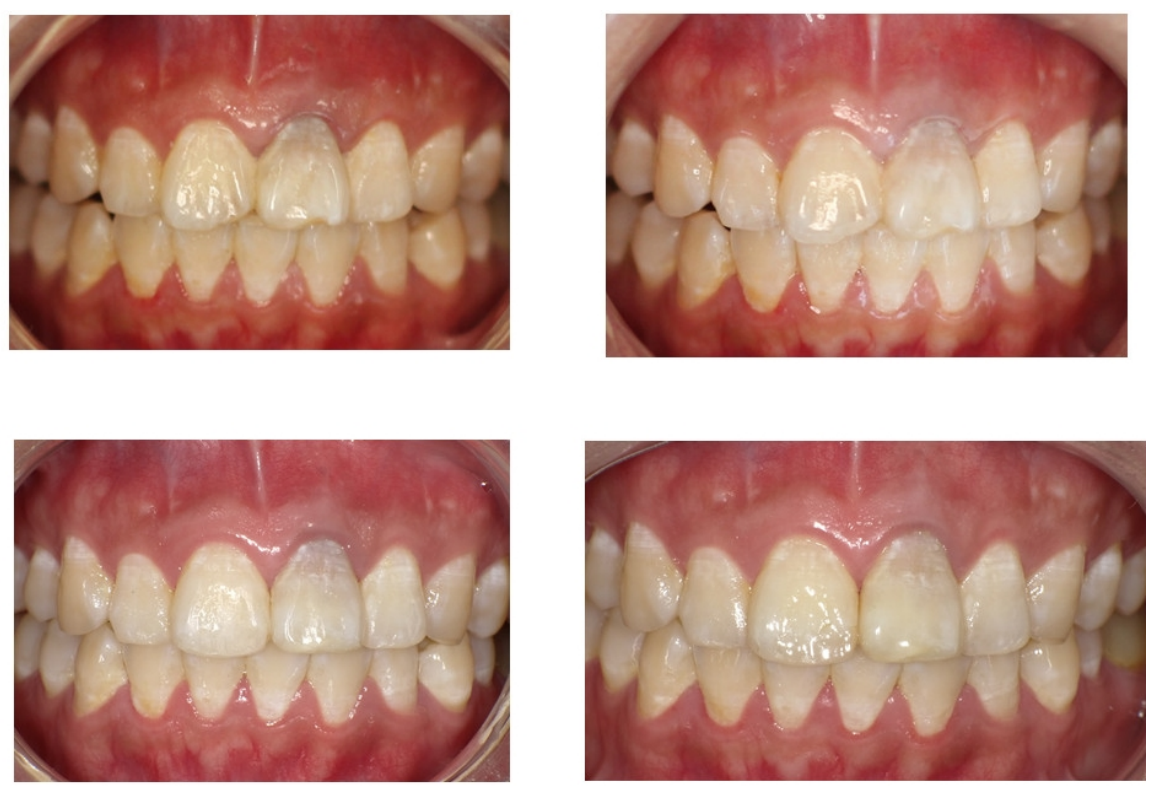

Figure 11. Bleaching effect four times.
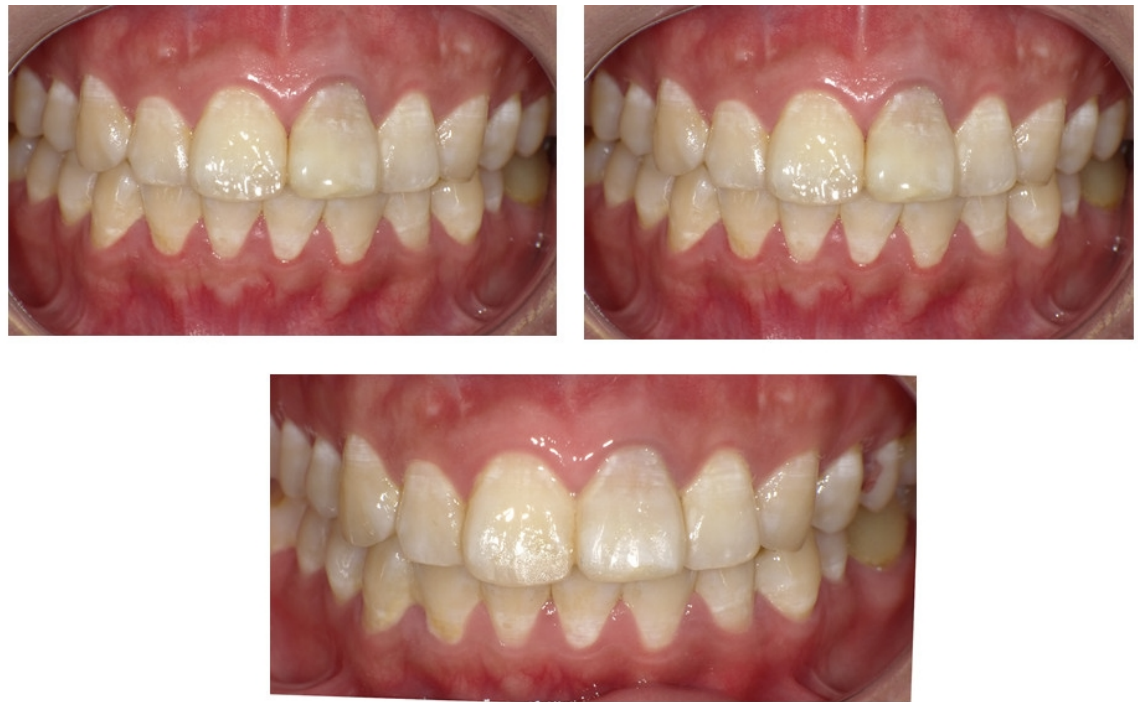

Figure12. Follow-up at 3, 6, 12 months after surgery.
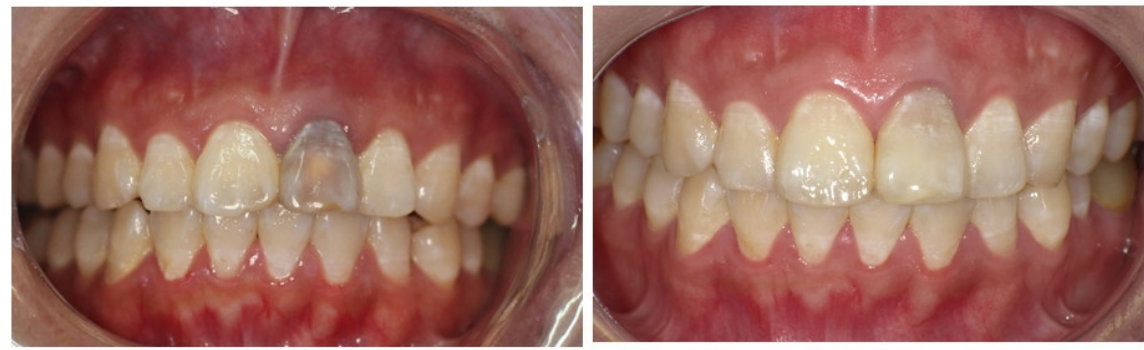

Figure13. Pre-operation and post-operation.

of urea peroxide which can form hydrogen peroxide by decomposition [6]. Intracoronal bleaching required the establishment of protective screen in tooth 
neck: "bobsled" screening form. It is recommended to use glass ionomer as material for establishing protective screen. However, this method is difficult to be operated in clinical to form a smooth and even shape. The color of tooth neck is difficult to be the same as that in tooth body after bleaching, while the color of tooth neck is often darker. Therefore, the protective screen should be as close to tooth root as possible. Moreover, more gutta-percha for root canal filling should be removed. However, it is difficult to ensure hydrogen peroxide cannot permeate to the open dentinal tubule and then spread to pariodontal cavity. Therefore, resorption in tooth neck occurred in later period.

Insufficient closure in tooth neck and decolorizer with high concentration may increase the risk of neck resorption. Patients should be informed about the risks of tooth neck resorption and stain relapse [7]. Early diagnosis of tooth trauma and root resorption can provide a better prognosis. Current study shows that the diagnosis of root resorption is related to patient age, trauma time and particularly tooth trauma [8]. The conclusion is that root resorption is a severe complication of tooth trauma. In particular, prolapses and embedded tooth trauma may further develop the root resorption. If tooth trauma causes root inflammation resorption, it is necessary to treat dental pulp in time to remove dead pulp and bacteria. In general, calcium hydroxide is used as intracanal medication to reduce root resorption [9]. Some studies recommend MTA for sealing apical foramen to treat external resorption in root inflammation caused by tooth trauma of young permanent teeth. Good therapeutic effects can be obtained [10]. Some studies show that it has been proved that using corticosteroidantibiotic intracanal as intracanal medication can effectively prevent and treat external inflammation and resorption [11]. Calcium hydroxide will not be used as the first seal for root canal therapy because of its inherent toxicity and irritation, but it can promote the repair of sclerous tissues as the follow-up seal.

After bleaching, aesthetic repair by resin was conducted for tooth with trauma causing tooth defect. Guide plate of silicon rubber is applied for pasting decoration at tongue side. Layering technique with light-cured composite is conducted for repair. Fine shine should be conducted after operation can realize good filling effects.

\section{Conclusion}

Improved root canal therapy can promote the healing and prevention of apical inflammation at apex. Without skilled person grasping hot gutta-percha filling method, pressure filling without restriction only causes failure of root canal therapy and even more severe problems (root resorption, root fracture, etc.). Extrusion of hot gutta-percha can be reduced by accurately measuring the working length of root canal, controlling the dynamics in vertical pressing, and X-ray examination before, in and after operation. The combination of skilled operating techniques with imageological examination is the guarantee for successful therapy.

\section{References}

[1] Clinton, K. and Van Himel, T. (2001) Comparison of a Warm Gutta-Percha Obtu- 
ration Technique and Lateral Condensation. Journal of Endodontics, 27, 692-695. https://doi.org/10.1097/00004770-200111000-00010

[2] Farzaneh, M., Abitbol, S., Lawrence, H.P. and Friedman, S. (2004) Treatment Outcome in Endodontics-The Toronto Study. Phase II: Initial Treatment. Journal of Endodontics, 30, 302-309. https://doi.org/10.1097/00004770-200405000-00002

[3] Yang, C., Sun, X., Pang, B. and Liu, L. (2014) Clinical Evaluation of Continuous Wave Hot Tooth Adhesive Vertical Filling Technology. Guangdong Dental Disease Control. No. 1.

[4] Peng, L., Ye, L., Tan, H. and Zhou, X. (2007) Outcome of Root Canal Obturation by Warm Gutta-Percha versus Cold Lateral Condensation: A Meta-Analysis. Journal of Endodontics, 33, 106-109.

[5] Zhang, W., Suguro, H., Kobayashi, Y., Tsurumachi, T. and Ogiso, B. (2011) Effect of Canal Taper and Plugger Size on Warm Gutta-Percha Obturation of Lateral Depressions. Journal of Oral Science, 53, 219-224. https://doi.org/10.2334/josnusd.53.219

[6] Kwon, S.R. and Wertz, P.W. (2015) Review of the Mechanism of Tooth Whitening. Journal of Esthetic and Restorative Dentistry, 27, 240-257. https://doi.org/10.1111/jerd.12152

[7] Zimmerli, B., Jeger, F. and Lussi, A. (2010) Bleaching of Nonvital Teeth. A Clinically Relevant Literature Review. Schweiz Monatsschr Zahnmed, 120, 306-320.

[8] Soares, A.J., Souza, G.A., Pereira, A.C., Vargas-Neto, J., Zaia, A.A. and Silva, E.J. (2015) Frequency of Root Resorption Following Trauma to Permanent Teeth. Journal of Oral Science, 57, 73-78. https://doi.org/10.2334/josnusd.57.73

[9] Cunha, R.S., Abe, F.C., Araujo, R.A., Fregnani, E.R. and Bueno, C.E. (2011) Treatment of Inflammatory External Root Resorption Resulting from Dental Avulsion and Pulp Necrosis: Clinical Case Report. General Dentistry, 59, e101-e104.

[10] Güzeler, I., Uysal, S. and Cehreli, Z.C. (2010) Management of Trauma-Induced Inflammatory Root Resorption Using Mineral Trioxide Aggregate Obturation: TwoYear Follow Up. Dental Traumatology, 26, 501-504. https://doi.org/10.1111/j.1600-9657.2010.00932.x

[11] Abbott, P.V. (2016) Prevention and Management of External Inflammatory Resorption Following Trauma to Teeth. Australian Dental Journal, 1, 82-94. https://doi.org/10.1111/adj.12400

Submit or recommend next manuscript to SCIRP and we will provide best service for you:

Accepting pre-submission inquiries through Email, Facebook, LinkedIn, Twitter, etc. A wide selection of journals (inclusive of 9 subjects, more than 200 journals)

Providing 24-hour high-quality service

User-friendly online submission system

Fair and swift peer-review system

Efficient typesetting and proofreading procedure

Display of the result of downloads and visits, as well as the number of cited articles

Maximum dissemination of your research work

Submit your manuscript at: http://papersubmission.scirp.org/

Or contact ojst@scirp.org 